\title{
CROSS-BORDER ASSIGNMENT - THE STUDY METHOD SUPPORTING INTERNATIONALIZATION OF SMES AND LINKAGE BETWEEN HEIS AND INDUSTRY
}

\author{
Maira Leščevica ${ }^{1}$, Eneken Titov ${ }^{2}$ \\ ${ }^{1}$ Vidzeme University of Applied Sciences, Latvia \\ ${ }^{2}$ Estonian Entrepreneurship University of Applied Sciences, Estonia \\ maira.lescevica@va.lv
}

\begin{abstract}
The variety of study methods used at universities still is conservative and more pragmatic, but there is an increasing tendency to change study methodology to more and more student-centred and to focus on the students' ability to become valuable workforce for SMEs. The necessity for development of study methods clearly demonstrates the research problem. At the same time, universities are facing pressure from governmental authorities to internationalize - student and teacher mobility, international partners and projects are highly recommended.

The main process at universities is the study process. But also internationalization should support the study process and students in achieving practice-based learning outcomes. Facing these challenges, NOBANET network of universities has elaborated and piloted the study method Cross-Border Assignments (CBA) linking students' future ability to successfully incorporate in the job market and the requirement for internationalization of studies.

The aim of this article is to introduce and assess the CBA as a method to involve student work and students to engage in entrepreneurship problems. The authors have collected and analysed feedback of 10 CBAs implemented in 6 different universities. The feedback was received by using questionnaires with mainly closed questions. The results show that companies are satisfied with students' work and they also appreciate teachers. The main conclusion about assessment of this method gives valuable contribution to scientific literature as a description of modern study method and good practice in linking HEIs and SMEs. Gratitude is expressed to the Nordic Council of Ministers for funding NOBANET project and project EKOSOC-LV, part 5.2.2. and INTERFRAME-LV.
\end{abstract}

Key words: Cross-Border Assignments, study method, NOBANET, Internationalization, SME.

\section{Introduction}

Internationalization of SMEs has a very high priority today in the main EU, interregional and national development plans. But many challenges like special support measures to increase SMEs' awareness of available opportunities have been identified in the internationalization process (e.g. European Commission, 2011; OECD, 2009).

At the same time, Higher Education Institutions (HEIs) have to adopt a third strategic direction called knowledge transfer (named also a third mission) in addition to teaching and research (Laukkanen, 2003; Van der Sijde et al., 2014; Trencher et al., 2013). HEIs constantly try to use various forms of cooperation in order to enhance competence development and competitiveness of SMEs. With the internationalisation of higher education, HEIs also expand their teaching and research to include cooperation with local and international partners (Jongbloed, Enders, \& Salerno, 2008). An important part of the strategy for HEIs is managing external relationships with industry. These findings give overview of actuality.

Close collaboration of HEIs and SMEs increases the capacity for regeneration and renewal in research, enhances the social impact of research and promotes the creation of new innovations and increases the competitiveness of the national economy as well as the development of the society that is based on knowledge and know-how. Universities, business and industry benefit from working together in flexible international partnerships. The university has a role in facilitating access to knowledge: scientific publications, seminars, workshops, and informal relationships can also be important ways of transfer of academic knowledge to the private sector (Şerbănică, 2011).

This article introduces a solution that can be used in creating useful relations between HEI, SME and students. Research is aimed at analysis of feedback from 10 Cross-Border Assignments (CBAs) implemented in 6 different universities, as experience from an ongoing Nordic-Baltic project NOBANET.

The research question is: can $\mathrm{CBAs}$ contribute and be used for the successful cooperation among cooperation partners like HEIs and SMEs.

The article has three main parts:

1) Insight to Nordic-Baltic Network for Internationalization of SMEs (NOBANET);

2) Cross-border assignment as a tool supporting SMEs internationalization;

3) Stakeholders' evaluation to the CBAs and its implementation process.

\section{Materials and Methods}

From the point of view of SMEs, Europe 2020 was the EU's growth strategy for the coming decade. The EU has a strategy to become a smart, sustainable and inclusive economy. These three mutually reinforcing priorities should help the EU and the Member States deliver high levels of employment, productivity and social cohesion (European Centre for the Development of Vocational Training, 2013). 
The Small Business Act (SBA) for Europe adopted in June 2008 and reviewed again in 2011 recognises the important role of SMEs in the economy and aims to promote SMEs' growth by helping them tackle barriers to go international that hamper their further development. The CBA seeks to provide support to SMEs to benefit from the growth of markets, in particular by providing support to improve access to international markets (European Commission, 2011). One of the possibilities for the SMEs to respond to those challenges is to cooperate with universities.

The main risks of cooperation are the lack of coordination and information problems. SMEs might also be afraid of so-called supplementary costs - public universities are known for standards and an excessive documentation with long and complex procedures and limits (Dan, 2013). Therefore, SMEs are more eager for the informal cooperation, because they are interested in a rapid and flexible access to economic and relevant information; they are mostly costsensitive and welcome the possibilities to cooperate without high-level bureaucracy and with low costs.

From the point of view of HEIs, in a knowledge society HEIs are expected to deliver value through teaching, research and knowledge transfer (Davey et al., 2014). At the EU level HEIs are asked to provide incentives for structured partnerships with the business community. HEIs should support the identification of those skills that graduates are expected to have when entering the labour market, develop appropriate governance structures, cooperate with companies to identify and provide appropriate training/retraining programmes, support the exchange, sharing and creation of knowledge through increased mobility between universities, research organizations and business (European Commission, 2009). Although there are some reasonable exceptions, cooperation between HEIs and business in Europe is still in the development stage (Davey et al., 2011).

What HEIs benefit from cooperation with SMEs among other outcomes are the design and delivery of programmes that are relevant to current and future business needs, ensuring progression opportunities at every level of achievement and a smooth transition between the different environments of universities and business. (Wilson, 2012). Dan (2013) adds that the main advantages for the teachers are that they can more freely choose study methodology, new research fields open, teachers have the possibility to test the study results, the new methods and techniques, subjects content can be updated with the cooperation results and also access to knowledge from the industry.

Many sources also point at obstacles for HEIs and business cooperation. The HEIs may have conservative management, lack of entrepreneurial culture and lack of incentives to individuals/academicians (Pukka,
2012). Also, lack of flexibility and responsiveness and overcomplicated systems and bureaucracy with poor communication ability have been named (Healey et al., 2014). Companies refuse cooperation because of HEIs' outdated curricula and academicians' poor ability to demonstrate cooperation value to employer and employee (Wedgewood, 2011). Both sides often emphasize lack of finances and time (Wedgwood, 2011), problems related to appropriation of results, communication problems, duration of the studies/ project and cultural differences (Mora-Valentin, \& Ortiz-de-Urbina-Criado, 2009), lack of mutual trust, difficulties in accessing resources for innovation, differences in objectives, organizational cultures, timetables and expectations, lack of appropriate structures (Şerbănică, 2011). The vast majority of academicians of all levels of HEI and business experience agree that funding barriers and bureaucracy within HEIs are the most relevant obstacles. (Davey et al., 2011). In general, the cooperation with business is an indicator for HEIs' competitiveness on the market for education services, trainings and research (Dan, 2013).

All background researches discussed in this article introduce the main reasons for HEIs and SMEs to go international and to develop necessary tool CBA to improve methods and methodology level of business study programmes in HEIs which joined the NOBANET network.

\section{Insight to Nordic-Baltic Network for} Internationalization of SMES (NOBANET)

The NOBANET programme worked out the methodology for cooperation of SMEs and HEIs in a study programme and at methodology level. The reality is that most academicians are not engaged at all in university- business cooperation (UBC) or only at a low level whereas at the institutional level, most HEIs engage to some degree of UBC (Davey et al., 2011).

NOBANET offers tools to achieve changes in HEI to develop entrepreneurial mind-set and achieve entrepreneurial institution (Källström \& Lescevica, 2014). The practical activities and tools at the study programme delivery level must support changes in HEI. The NOBANET idea started as a network of universities - Arcada UAS (FI), Vidzeme UAS (LV), University of Acureyri (IS), Estonian Entrepreneurship UAS (EE), TTK UAS (EE), Kauno Kolegija/UAS (LT), School of Education and Communication at Jönköping University (SE), Westerdals Oslo School of Arts, Communication and Technology (NO), Lillebaelt Academy (DK), and SME support institutions Valmiera Business and Innovation Incubator (LV), GO International Finland (FI), AIESEC in Finland, Union of professional business graduates in Finland in 2013. International markets offer substantial opportunities for SMEs, but SMEs face challenges in access to 
Table 1

A matrix format explanation of cooperation between HEIs and SMEs (Compiled by the authors, according to the presentation materials of NOBANET, 2017)

\begin{tabular}{|c|l|l|l|l|}
\hline Beneficiaries & \multicolumn{1}{|c|}{ Students } & \multicolumn{1}{c|}{ HEI } & \multicolumn{1}{c|}{ SME } & \multicolumn{1}{|c|}{ Faculty/academicians } \\
\hline \multirow{5}{*}{$\begin{array}{l}\text { Results from the } \\
\text { programme }\end{array}$} & These topics & $\begin{array}{l}\text { Potential and new } \\
\text { students }\end{array}$ & Potential employees & E-learning tools \\
\cline { 2 - 5 } & Practical examples/ & $\begin{array}{l}\text { Equipment } \\
\text { (software) }\end{array}$ & Expertise & $\begin{array}{l}\text { NOBANET network and } \\
\text { virtual resources }\end{array}$ \\
\cline { 2 - 5 } & Potential jobs & Finances & $\begin{array}{l}\text { Rise of competences } \\
\text { (target market knowledge) }\end{array}$ & $\begin{array}{l}\text { New teaching } \\
\text { methodology and tools }\end{array}$ \\
\cline { 2 - 5 } & Internship places & Research projects & Competition advantages & Practical experience \\
\cline { 2 - 5 } & Research projects & Reputation & Reputation & Contacts with enterprises \\
\cline { 2 - 5 } & $\begin{array}{l}\text { Foreign language } \\
\text { and teamwork skills }\end{array}$ & Up to date curricula & Trainees & \\
\hline
\end{tabular}

foreign market information and financing, locating customers and understanding cultural differences (European Commission, 2011).

Data about SMEs in the EU can be found in many annual reports of the European Union (European Commission, 2011). They provide an overview of the size, structure and importance of SMEs and their contribution to growth and jobs.

The overall aim of NOBANET is to create and widely disseminate new knowledge on successful internationalization of Nordic and Baltic SMEs. This aim is achieved through close cooperation between HEIs and SMEs in 6 Nordic and Baltic countries.

Faculty, students and companies work closely together and across national borders, within educational courses and through cross-border assignments in companies (NOBANET, 2017).
The objectives of NOBANET are to:

1. Develop new learning materials on internationalization of SMEs;

2. Implement real-life projects on internationalization;

3. Develop partner HEIs curricula to include internationalization of SMEs;

4. Create models for sustainable cooperation between HEIs and SMEs.

Particularly, the second task is aimed at the CBA development and the fourth is aimed at the promotion of cooperation between HEIs and SMEs. NOBANET management team also has developed and presented more matrix type models (NOBANET, 2017) (Table 1).

NOBANET management group recently developed cooperation model, which was accepted and adopted by all stakeholders. This model shows the main tools

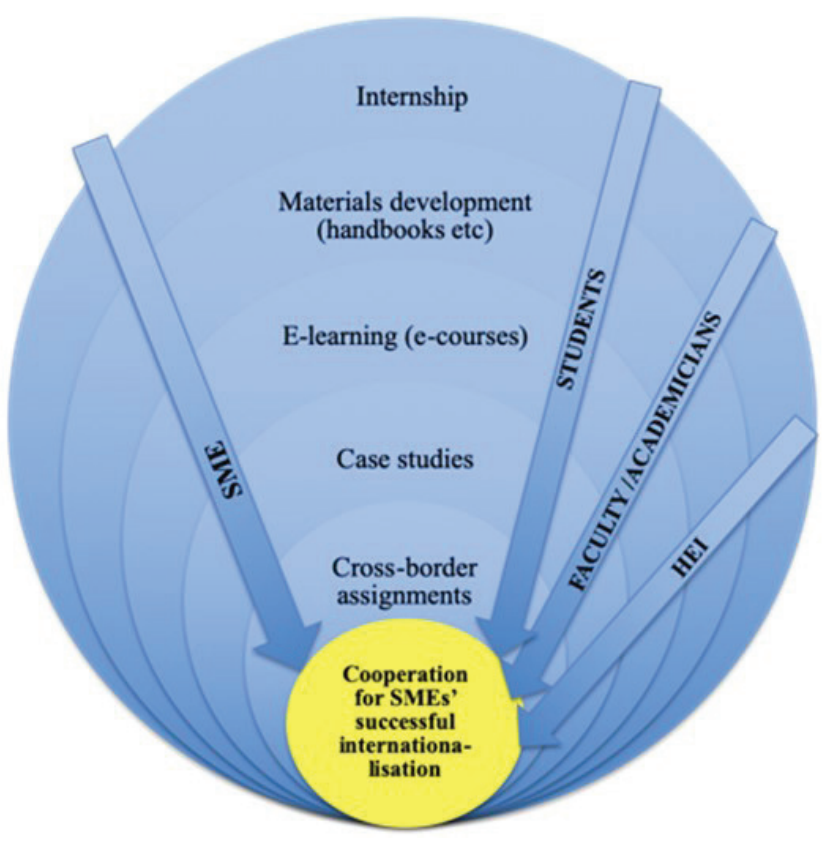

Figure 1. HEIs and SMEs cooperation model for successful internationalization (Created by the authors). 
at study delivery level, which are used to gain the expected results (Figure 1). The model also gives a possibility to use it for describing and presenting NOBANET project results and goals.

In the present article, we focus on the cross-border assignment as one of the most powerful and simple tools to achieve quick and clear results in the field of SME and HEI cooperation. The tool enables to get practical experience and feeling of success and therefore motivates all the parties to continue with cooperation even on a larger scale.

2. Cross-border assignment as a tool supporting internationalization of SMEs

The Cross-border Assignment (CBA) is a tool for mediating the companies' research tasks for the target country's students. The CBA's main purpose is to support development and internationalization of SMEs and to offer students real-life assignments. The assignments take place in Nordic-Baltic teams where businesses and students work together over national borders.

Real-life cross-border assignments also provide incentives to try out new and innovative teaching methods. To get a better idea of the nature of the CBAs, one example is described. Icelandic company, Inspiration Iceland, was interested in entering the Finnish market, and through NOBANET programme they asked students of Arcada UAS to do marketing surveys to find the right customer segment for them.

Through this assignment, the students gave valuable information to the company about the potential of the Finnish market, possible customer segments and input for marketing campaign. The company now is preparing to enter the market. The CBA implementation process (Figure 2) starts from the NOBANET project coordinator and SME to describe the SME's needs concerning the internationalisation and idea how the students can help to meet those needs. The CBA description is prepared together. NOBANET also secures that SME's needs are taken into consideration in a structured way in education. If needs of the SME are different, the CBAs can, for example, help SMEs to develop international market entry plans, create communication materials, produce case stories, participate in international business fairs, test products and services, cooperate in work placements abroad and many more.

CBA is useful for all the three involved parties students, universities and SMEs. For the students, the assignment will lead to a more output-driven learning experience. There are multiple reasons why SMEs should cooperate with the target country (market in which SMEs would like to enter) HEIs through NOBANET. First of all, through this cooperation SMEs have the access to the researchers (students and teachers/experts) who understand the culture, environment and local peculiarities of the target country. This, in turn, ensures that activities are suitable for the target market and other solutions, which are based on requirements, traditions and best practices of the target country. Research in the target country is already the first stage in the market entry process

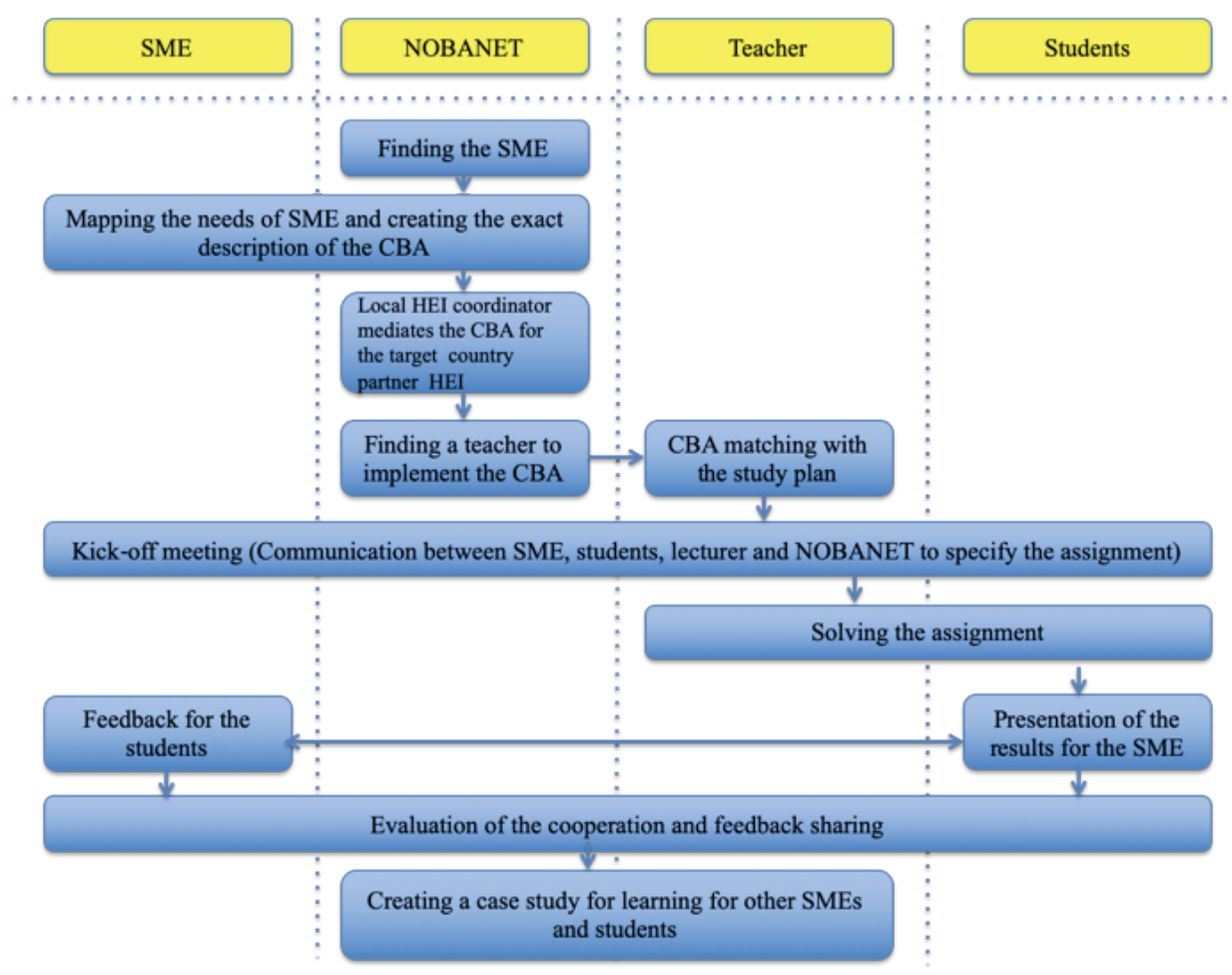

Figure 2. CBA implementation process (Created by the authors). 


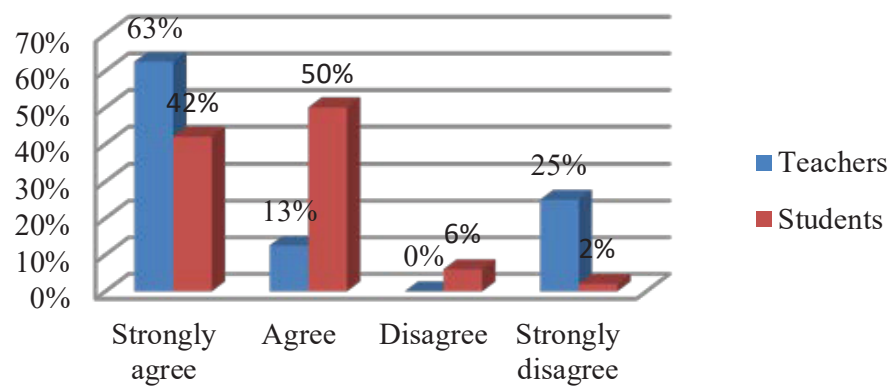

Figure 3. CBA's relevance for study method, \%.

Source: created by authors.

and activities through CBA implementation process already start to introduce the SMEs' product or service in the target country. The first positive contact between an SME and an HEI may lead to further in-depth cooperation - new researches, product development, internship, employment, etc. The NOBANET project has already increased cooperation between HEIs and SMEs.

3. Stakeholders' evaluation of the CBAs and its implementation process

The main idea of this evaluation is to assess the CBA as a study method from the perspective of the involved parties - academicians/teachers, students and SMEs or in other words - stakeholders. The evaluation method included all six HEIs participating in the programme and the main result was that altogether 8 CBAs were implemented during the project. The evaluation methodology included questionnaires for key participants - teachers, students and SMEs representatives. Questionnaires contained only closed questions. The main data collection method was filling out the questionnaires printed on paper or registered online. The main process of the CBA implementation is given in Figure 2 and also the evaluation steps are brought out. The data collected from this evaluation is the main origin for this research. The teachers also were asked to comment on the CBA from the pedagogical point of view. Altogether, evaluation is based on feedback of 9 teachers, 76 students and 9 representatives of SMEs. Three different questionnaires were used to collect feedback - students', teachers' and SMEs' feedback questionnaires.

All forms included open and closed questions, some of the questions were similar to allow comparing stakeholders' opinions. Also, the structure of the questionnaires was similar, starting with the questions about general satisfaction of the process and method, then questions about the method implementation process and concluding with suggestions for the future.

\section{The main results of this survey}

The outcome from the usage of CBAs was evaluated by teachers and students. In most cases, teachers and students are satisfied with working on real life cross border assignments (Figure 3).

Teachers also acknowledge that during the particular project students learned a lot about the particular topic, which was the focus of the CBA (Figure 4). Teachers identified that there could be more detailed case descriptions, but, in most cases,

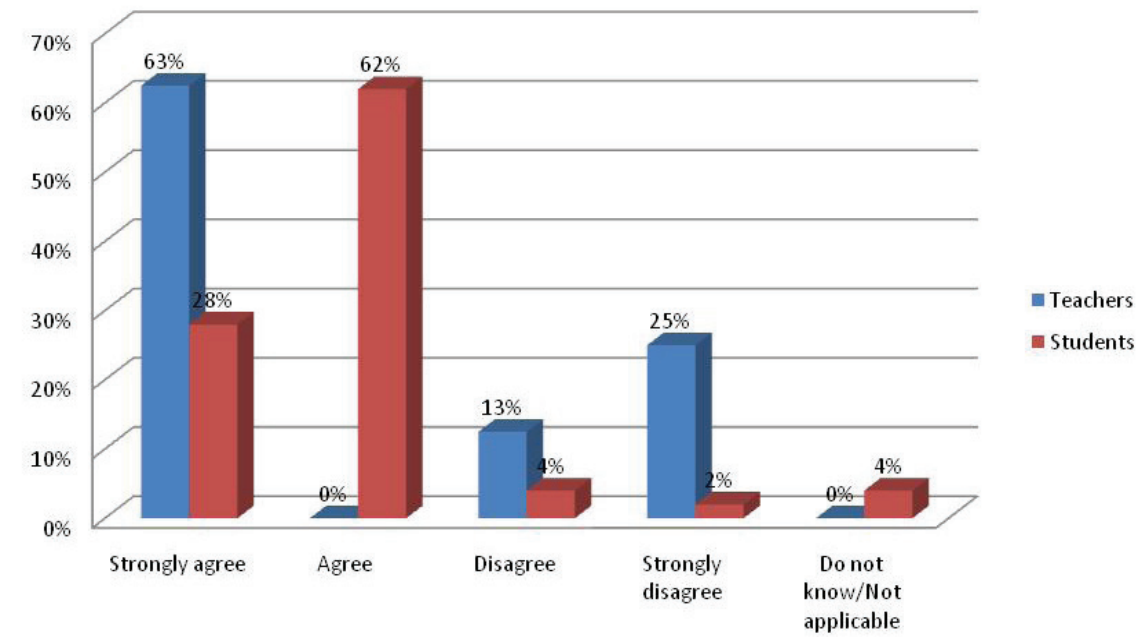

Figure 4. CBA's suitability to learn specific topic, $\%$.

Source: created by authors. 


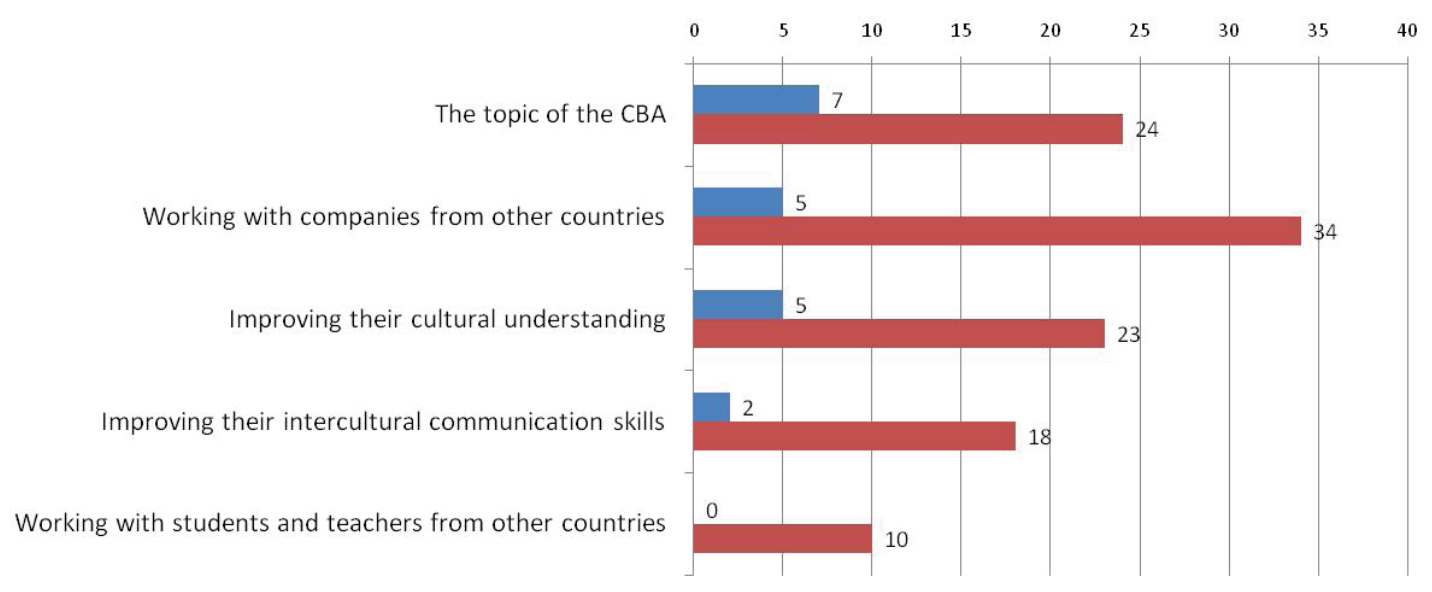

Figure 5. The most valuable aspects of CBAs, weighed numbers.

Source: created by authors.

it was compensated with answers from companies. It was also recognised that students and teachers were lucky to have new cases instead of the usual ones.

Teachers brought out that in some cases CBA helped to learn general key-competences and CBA's support to increase specific competences depends on the aim and content of the CBA.

Real partnership among students, teachers and companies, possibility to apply theory to practice were mentioned as the biggest benefit from collaboration with the company.

Teachers and students were also asked to validate certain aspects of the assignment. They were allowed to choose three aspects maximum. The evaluation results are in Figure 5.

Besides, teachers were asked what they would do differently if they had a chance to do the same assignment again. Four teachers did not want to change anything. Some teachers and students acknowledged that they would form smaller groups (one group had 8 and more students). Teachers would investigate more about the case before choosing it - whether there is enough information and whether the company and students are both interested in the result. Students identified that they would divide roles more specifically in the group, making sure that all are participating and investing effort.

From the pedagogical aspect, the teachers brought out also some other nuances concerning CBA implementation. As most of the CBAs were about target market research, the teachers highly appreciated that dealing with CBA situation gave students a wide range of possibilities to demonstrate the main skills in applying basic economic and business management theories and economic activity regulation principles in making managerial decisions, analysing and evaluating the changing business environment, adopting timely and cost-based decisions ensuring the efficient operation of organizations (companies).
SME representatives highly evaluated the possibility to give real-life tasks to students. They also appreciated the chance to learn from reports. Companies identified importance to investigate potential market before entering. The strong point is a fresh look at their everyday life problems that they have evaluated as highly professional. Finally, they acknowledged that they got very valuable information by paying nothing more than time and effort to help with information supply on time. This is highly appreciated by students and academic staff and CBA implementation should be continued and developed as training method for sharing with other HEIs.

\section{Conclusions}

The aim of the present article is to introduce and assess the CBA as an appropriate method to get entrepreneurs to involve student work and students to engage in entrepreneurship problems. The aim is fulfilled and also gives the answer to the research question.

NOBANET as a project is very important for establishing common relationship between different universities in 6 countries and SMEs. Especially those SMEs that joined the project with their cross-border assignments (CBA), were the first pioneers to explore the system to see whether it works in the favour of internationalization. All the stakeholders involved in CBA confirmed that this study method is useful for all parties. CBA is the main tool in NOBANET project to support internationalization of SMEs. The model of cooperation for internationalization has been tested and approbated.

During the project and according to the participants' feedback, also the drivers and obstacles of the model and CBAs are clearly identified.

In general, the main drivers are:

- Undertaking of joint field study/research;

- Production and collection of study materials; 
- Co-creation of long-term economic, cultural and social benefits;

- Co-creation of grasp between study and work, theory and practise;

- Coaching students how to network, cooperate;

- Development of a critical, demanding and innovative approach to the study process and real-life cases;

- Enabling the use of modern learning technologies (e-learning).

At the same time also the obstacles were clearly identified and the most important for all the parties were misunderstandings because of poor communication - unclear goals and expectations, weak language skills, too infrequent communication, etc. For the future research, parties also brought out the problems concerning the organisation of joint work/ division of responsibilities and belated interest from SME representative during CBA. Despite the above mentioned obstacles, all the implemented CBAs were successful and supported internationalization of SMEs and gave valuable information to start using CBA as a study method in higher education. Therefore, the new method introduced and assessed gives already significant contribution to the existing network of HEIs in NOBANET. Information about this method has been and will be disseminated to other HEIs and SMEs. The CBA method will be more researched in the next application rounds and developed further. The novelty of this method so far puts emphases on learning environments, where universities and businesses collaborate over distances, crossing borders and jointly creating new knowledge that helps to strengthen internationalization of HEIs and SMEs.

\section{Acknowledgement}

Gratitude is expressed to Nordic Council of Ministers for funding NOBANET project and project EKOSOC-LV, part 5.2.2. and INTERFRAME-LV

\section{References}

1. Dan, M-C. (2013). Why Should University and Business Cooperate? A Discussion of Advantages and Disadvantages. International Journal of Economic Practices and Theories, Vol. 3, No. 1, pp. 67-74.

2. Davey, T., Baaken, T., Muros, V.G., \& Meerman, A. (2011). Final Report - Study on the cooperation between Higher Education Institutions and public and private organizations in Europe. Science-to-Business Marketing Research Centre.

3. Davey, T., Plewa, C., \& Muros, V.G. (2014). University-Business Cooperation Outcomes and Impacts - A European Perspective. Springer Fachmedien Wiesbaden, pp. 161-176.

4. European Centre for the Development of Vocational Training. (2013). Identifying skills needs. Retrieved March 13, 2019, from http://http://www.cedefop.europa.eu/EN/identifying-skills-needs/index.aspx.

5. European Commission. (2009). Commission of the European Communities Staff Working Document SEC (2009)/ 423 on accompanying the Communication on 'A new partnership for the modernization of universities: the EU Forum for University Business Dialogue. Impact Assessment'.

6. European Commission. (2011). Opportunities for the Internationalisation of European SMEs. Retrieved March 13, 2019, from http://bookshop.europa.eu/en/opportunities-for-the-internationalisation-ofeuropean-smes-pbNB0414189/.

7. Healey, A., Perkmann, M., Goddard, J., \& Kempton, L. (2014). Measuring the Impact of University Business Cooperation (EAC/23/2012). Final Report.

8. Hjálmarsdóttir, H.B., \& Kristjánsdóttir, V.K. (2015). Pilot study - results from students, presentation materials, Jönköping, NOBANET.

9. Jongbloed, B., Enders, J., \& Salerno, C. (2008). Higher Education and Its Communities: Interconnections, Interdependencies and a Research Agenda, Higher Education. No. 56, pp. 303-324. DOI: 10.1007/s10734008-9128-2.

10. Källström, E., \& Lescevica, M. (2014). University-Business Cooperation for the Internationalisation of SMEs. Presented and digitally published extended abstract on $12^{\text {th }}$ Annual BMDA Conference 'A Successful $21^{\text {st }}$ Century Organization'. Riga, Latvia: May 7-9, 12 pp.

11. Laukkanen, M. (2003). Exploring academic entrepreneurship: drivers and tensions of university-based business. Journal of Small business Enterprise Development. Vol. 10, No. 4. pp. 372-382.

12. Mora-Valentin, E.V., \& Ortiz-de-Urbina-Criado, M. (2009). Improving the effectiveness of academicbusiness models: an analysis of obstacles in R\&D activities in service industries. Service Business. December 2009, Vol. 3, Iss. 4, pp. 395-413.

13. NOBANET. (2017). Presentation materials, Retrieved March 13, 2019, from www.nordicbalticnet.info.

14. OECD. (2009). Top Barriers and Drivers to SME Internationalisation. Report by the OECD Working Party on SMEs and Entrepreneurship, OECD.

15. Pukka, J. (2012). Higher Education and City/Regional Development in a presentation to the OECD Roundtable. 
16. Şerbănică, C. (2011). A Cause and Effect Analysis of University - Business Cooperation for Regional Innovation in Romania. Theoretical and Applied Economics. Vol. XVIII, No. 10(563), pp. 29-44.

17. Trencher, G., Yarime, M., McCormick, K-B., Doll, C., \& Kraines, S.B. (2013). Beyond the third mission: Exploring the emerging university function of co-creation for sustainability. Science and Public Policy.

18. Van der Sijde, P., David, F., Frederik, H., \& Carretero, M.R. (2014). University-Business Cooperation: A Tale of Two Logics. Springer Fachmedien Wiesbaden. pp. 145-160.

19. Wedgwood, M. (2012). Higher Education for the Workforce: Barriers and Facilitators to Employer Engagement, DIUS Research Report 08 04, Retrieved March 13, 2019, from http://dera.ioe.ac.uk/8724/.

20. Wilson, T. (2012). A Review of Business-University Collaboration. Retrieved March 13, 2019, from https://www.gov.uk/government/uploads/system/uploads/attachment_data/file/32383/12-610-wilsonreview-business-university-collaboration.pdf . 